\title{
The Determinants of Information Technology Towards Innovation Performance in Iraqi SMEs
}

\author{
A. Hayder, Samer Ali Al-shami, W. Raad, Nurulizwa Rashid, Z. Jasim
}

\begin{abstract}
Information technology has inevitably perceived as a core source for the competitive advantages of SMEs. It facilitates innovation capabilities through transforming the needed knowledge that is important for new product, services, market, organizational and processes development. Yet, the literature on the application of IT on innovation abilities still suffering to empirical research, especially from developing countries. Therefore, this article aims to examine the role of IT infrastructure on innovation capabilities in Iraqi SMEs. The survey was used to gather data and regression analysis carried to analysis the data. The finding of this paper emphasizes that IT infrastructure (IT connectivity, modularity and personal) has positive effect on innovation performance in Iraqi SMEs.
\end{abstract}

\section{INTRODUCTION}

Information Technology (IT) allows us to save time and do a more effective management and improve information, since it facilitates access to key knowledge. Thus, advances in information technology have promoted substantial changes in business settings, especially in business practices by shortening productive cycles, allowing fast technological development and finally originating hyper-competitive surroundings (Ochara \& Mawela 2015). Thus, companies with a high capability of introducing fast changes and adapting to new technologies can develop more competitive advantages than slower and less informed competitor (Koo et al. 2016). However, some studies do not support the positive relation between IT and company performance (Devaraj \& Kohli 2003). An explanation for this may be that IT represents a necessary but insufficient resource to achieve competitive advantages. Many researchers on strategic management relate it with other specific components of a firm's strategy as well as with components derived from the Resource Based View (Quek 2017)

Revised Manuscript Received on April 12, 2019.

A. Hayder,UniversitiTeknikal Malaysia Melaka, The Faculty of Technology Management and Technopreneurship, Institute of Technology Management and Entrepreneurship, Faculty of Information and Communication Technology.

Samer Ali Al-shami, UniversitiTeknikal Malaysia Melaka, The Faculty of Technology Management and Technopreneurship, Institute of Technology Management and Entrepreneurship, Faculty of Information and Communication Technology

W. Raad, Dijlah University College, The Faculty of Technology Management and Technopreneurship, Institute of Technology Management and Entrepreneurship, Faculty of Information and Communication Technology.

Nurulizwa Rashid, UniversitiTeknikal Malaysia Melaka, The Faculty of Technology Management and Technopreneurship, Institute of Technology Management and Entrepreneurship, Faculty of Information and Communication Technology.

Z. Jasim, UniversitiTeknikal Malaysia Melaka, The Faculty of Technology Management and Technopreneurship, Institute of Technology Management and Entrepreneurship, Faculty of Information and Communication Technology
The latter states that not only are information technology investment important, but it will also be a key element like organizational learning and internal knowledge. The concept of "knowledge as resource" suggests that knowledge can be transmitted, combined, and used for value creation (Grant 1996). Therefore, creation and effective knowledge transfer can contribute towards the development of competitive advantages. Reconfiguration of resources is essential, since it provides a dynamic capability to coordinate, expand and explore new knowledge and develop new operational competences (Hashem et al. 2015). Due to changing environment conditions, firms need to adapt interna knowledge base in order to succeed in changing markets. The capacity to set up knowledge base has been considered by some academic as a dynamic capability. The learning internally refers the process of creating new knowledge where company's accumulation of skill and competencies In contrast, learning externally, indicates to the process in which the knowledge integrated inside the company by interrelating with the setting and other companies.

Knowledge creation and use are associated with innovation, since the latter is related to successful exploitation of new ideas.It can consider the commercial success of innovation as an approximation to overall performance, since it has been suggested in the literature that companies with higher innovation capability obtain greater overall performance (Cui et al. 2015; Rashid et al. 2015). Despite past research has tested the relationship between IT competency,knowledge or learning and company performance (Tallon \& Pinsonneault 2017), these have been inconclusive( Devaraj and Kohli, 2003). In order to deepen the thoughtful of the above relationship, this research includes a new dependent variable closely linked to business results, the commercialsuccess of innovation.Previous studies consider that innovation capability has a direct effect on a firms' overall performance.Thus, this research aims to examine the association between IT competencies and innovation competences. Even though information technology has also been credited as a core of firms' competitive advantage, the technological factors that affect innovation activities have not received an adequate attention, especially in developing countries. Therefore, this paper investigates the role of IT competencies on innovation capabilities in the Iraqi SMEs which is one of very few papers that have conducted in the Arab region. 


\section{LITERATURE REVIEW}

RBV has been broadly utilized as a managerial framework to determine key strategic assets with the possibility of yielding a comparative advantage over their competition. Since the social network sites assume a fundamental role in information and knowledge acquisition which are the main elements in innovation development and also absorptive capacity, RBV is utilized as a focal point to scrutinize the link between innovation performance and SNSs.Nevertheless, the resource-based view has been faulted for several reasons, for example, it doesn't consider how key capacities are acquired, the role of products markets is unexplored in the contention and it disregards the external factors that influence a firms' competitive advantage. The resource-based view has been criticized for several reasons including the lack of consideration of how the key capabilities are acquired, the role of product markets is underdeveloped in the argument and it ignores the external factors that affect the firms' competitive advantage.Despite, the criticisms of RBV, it is used widely and by recent research to determine the strategic resources such as technological competencies having the potential leverage and comparative advantage to an organization via innovation. In this research, RBV will be used as a lens to guide the researcher in determining the IT competencies that influence innovation performance. To tackle the aforementioned criticisms, this research introduces an IT competencies as independent variable to find out how IT competencies influence innovation performance. Based on the resource-based view asset-based view (RBV), sustainable competitive advantage is plausible when a firm has capabilities and resources. Consequently, SMEs abilities to expand their execution are considerably enhanced through social media.The resource-based view of an organization fosters a link between web-based social networking use and value creation together with the start-up of additional SMEs.

\section{INNOVATION CAPABILITIES}

Innovation is hypothesized in a multiplicity of methods. OECD (2005: 46) defines innovation as "implementing an original or enhanced product (services or goods), a method, a new advertising and marketing approach, or a new managerial practice". OECD (2005: 17) differentiates between types of innovations: product, process, managerial and marketing. Product innovations contain considerable adjustments in the abilities of services or products, including new services and goods as well as major enhancements to present products. Process innovations are seen as a significant alternation in manufacturing and delivery approaches. Meanwhile, organizational innovations can be seen as an application of new management techniques, and these modifications can be in the practices of business enterprises, rather than the company's business or outside relations. Innovations at the marketing level include the application of innovative marketing techniques, which comprises modifications in product and service design or packaging, modification of the advertising process of the products or services and placement, as well as pricing approaches. In general, the literature on the subject matter considers innovation as a crucial key for sustainable firm success, especially in dynamic markets (Camisón \& VillarLópez 2014; Rashid, N., \& Shami 2017). The underlying logic of this idea is that innovation frequently assists in coping with an uncertain environment.Based on the Schumpeterian view, companies have to be capable of keeping up with growing complexity and high-speed alteration. In such contexts, enterprises with the aptitude to innovate will be capable to react to the defies quicker, manufacture upgraded new services, products, and efficiency exploit opportunities as compared to noninnovative enterprises (Wadho \& Chaudhry 2018).

\section{Table 1: Innovation}

\begin{tabular}{|l|l|}
\hline Innovation Performance & References \\
\hline I1: Repeatedly attempts out new ideas & OECD (2005: \\
I2: Pursues new methods to do things; & 46)(Camisón \& \\
I3: Innovative in its techniques of & Villar-López \\
$\quad$ operation; & 2014) \\
$\begin{array}{l}\text { I4: Since five years, new product } \\
\quad \begin{array}{l}\text { introduction has increased in our } \\
\text { firm }\end{array}\end{array}$ \\
\hline
\end{tabular}

\section{INFORMATION TECHNOLOGY INFRASTRUCTURE}

IT infrastructure flexibility is described based on IT organic compounds which include connectivity, compatibility, modularity and personality.IT can facilitate strategic flexibility, which still unsettled, through providing a strong connection infrastructure, integrating Information System applications incorporating different functionalities and utilizing database-oriented applications regularly in daily operations (Chen et al. 2017).Compatibility is defined as the capacity to share data and information across varying component technologies across the organization helping traverse formal limits enabling employees to access the data, information and knowledge existing inside the organization thus making it a valuable resource (Isal et al. 2016). The adaptability of IT infrastructure is dependent on the changes related to the tone of innovation technology fitness and competitive advantages (Swanson \& Ramiller 2017). Association between (IT) and performance of a firm are important themes that have ruled the information system study for evaluating the ability of the company take advantage of IT (Chae et al. 2014). Modularity quality turned out to be more imperative today in light of the expanded multi-faceted nature of current innovation. Modularity denotes what degree of Information technology infrastructure might be disengaged and reassembled (Schilling 2000). Modularity is the limit of the IT infrastructure to include, alter, and push off any information segments or programming segments effectively without major antagonistic impacts.

A modular framework takes into account a broad assortment of information, programming, and differed innovative advances to be diffused into its general business structure. Generally, the execution of Enterprise Resource Planning (ERP) has been elevated to incorporate extra 
modules in the customary center modules for SCM, for example, client relationship, production, data warehousing, computerization and information warehousing (Dai 2008). The adjustment in tone is a term, for the most part, utilized in the control of software engineering and data innovation. Modifications to the tone allude back to making distinctive modules first and after that connecting them to create a total framework (Tsuji et al. 2016). Changes in tone permit ease of re-use and lessen replication. Besides, the convenience and changes in tone make it simpler to determine issues, for example, bugs empowering recognize ability so as to influence modules. This confines the extent of the offence to a particular point (Chae et al. 2014). The modularity dynamic suggests that respondents of the survey recognize the trend towards quicker submission enlargement (e.g., eco-friendly object-oriented technologies software modules). Additionally, the second-order factor infers that access control (e.g., transparency) is critical, as present-day associations must be equipped to disseminate information quickly and to a more extensive scope of clients. In this study, information transparency is characterized as free recovery and streaming of information between approved personnel in an organization or between organizations unrestricted to a specific area or location.Several researches have shown that flexibility is completely related with strong performance. For instance, manufacturing organizations had reviews and stated that there is a strong link between flexibility and strong performance in their organizations (Brunswicker \& Vanhaverbeke 2015).

\section{IT COMPETENCIES AND INNOVATION PERFORMANCE}

In the course of the previous decade, there has been a developing interest in the significance and the worth of IT for the organizations. Majority of the researchers neglected to affirm the immediate effect of IT on business outcome. (Pérez-López \& Alegre 2012) stated that the motive behind this irregularity is presumably is in the failure of the creators to take into account different organizational dimensions technology and performance. Most IT research is centered around the examination of the variables affecting its adoption where the dissected components can be arranged into three classifications: factors identified with the organizations' staff that will utilize IT, factors identified with the organizations' attributes and factors identified with the external setting in which the firm functions (Ollo-López \& Aramendía-Muneta 2012). Its effect on firms' innovativeness is rarely analyzed, for the most part, as the impact of a specific innovation to a specific group of innovation. In (Ollo-López \& Aramendía-Muneta 2012)study, they examined the effects of IT on innovation and competitiveness by showing that just the utilization of different IT solutions doesn't influence the glassy of competitiveness, nor influence the glassy of innovation of the organization. However, (Turulja \& Bajgoric 2016) examines the relationship between IT competencies and innovation performance among Bosnia and Herzegovina. This study used a purposive sampling strategy in a sample selection (using 444 questionnaires) due to the small market and to ease the classification. The result of structured equation model (SEM) shows a significantly positive association between IT competencies and innovation performance.

\section{METHODOLOGY AND ANALYSIS}

The survey sent to 220 SMEs in Iraq through Facebook and Survey Monkey. But, the response was 181 firms 19 of them excluded due to not accomplished and the entire quantity of finished questionnaires were 162 firms.

Table 2: IT Infrastructure

\begin{tabular}{|c|c|}
\hline $\begin{array}{l}\text { Independent Variables } \\
\text { Items Compatibility }\end{array}$ & Hypotheses \\
\hline $\begin{array}{l}\text { 1. } \\
\text { 2. } \text { IT section multiple interfaces or entry topics } \\
\text { 3. data kinds, counting text, voice, and graphics } \\
\text { 4. } \\
\text { numerous lines or admission plugs }\end{array}$ & $\begin{array}{l}\text { H1:IT compatibility } \\
\text { positively associated } \\
\text { innovation performance }\end{array}$ \\
\hline \multicolumn{2}{|l|}{ Items Modularity } \\
\hline 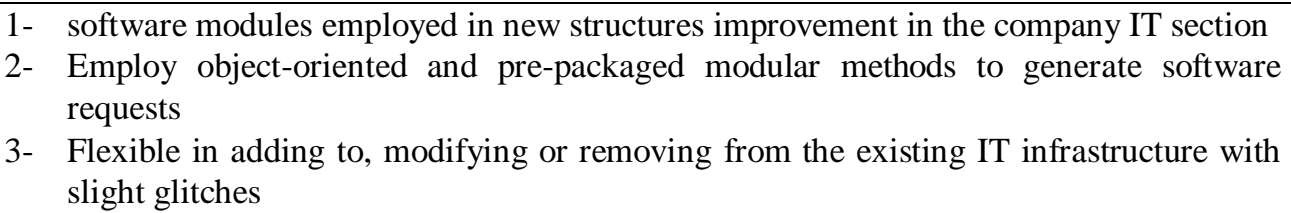 & $\begin{array}{l}\text { H2: ITmodularity is positively } \\
\text { associated with innovation } \\
\text { performance }\end{array}$ \\
\hline \multicolumn{2}{|l|}{ Items Connectivity } \\
\hline $\begin{array}{ll}1- & \text { suppleness in its relations and networks } \\
2- & \text { have electronic links and influences through the whole company } \\
\text { 3- } & \text { Responsiveness in using by the operators }\end{array}$ & $\begin{array}{l}\text { H3: IT connectivity is } \\
\text { positively associated with } \\
\text { innovation performance }\end{array}$ \\
\hline
\end{tabular}

Items Personal Resources 
1- $\quad$ work excellently in cross-functional players addressing business glitches

2- have the capability to work helpfully in a assignment team setting

3- skilful in numerous know-hows and tools

4- Stimulated to absorb new knowledge and technologies

H4: Personal Resources is positively associated with innovation performance

The sample was gathered from six type of businesses divided into two sectors namely industrial as well as service sectors as shown in Table 3.

Table 3: Data Distribution and Collection according to industrial sector and company types

\begin{tabular}{|l|c|c|c|c|c|}
\hline \multicolumn{1}{|c|}{ Type of industry } & Sector & Distribution & Received & Valid & Percentage \\
\hline Oil Industrial & Industrial & 40 & 32 & 30 & $75 \%$ \\
\hline Health industry & Service & 38 & 31 & 28 & $74 \%$ \\
\hline Communication & Service & 36 & 30 & 27 & $75 \%$ \\
\hline Hotel industry & Service & 37 & 27 & 25 & $68 \%$ \\
\hline Leather industry & Industrial & 34 & 28 & 25 & $74 \%$ \\
\hline Food industry & Industrial & 35 & 25 & 27 & $77 \%$ \\
\hline \multicolumn{2}{|r|}{ Total } & 220 & 173 & 162 & $74 \%$ \\
\hline
\end{tabular}

Table 5: Coefficients

\section{RESULTS}

As shown in Table 3, the overall results show that the instrument has a high reliability standard

\section{Table 4: Cronbach's Alpha for Reliability}

\begin{tabular}{|l|c|c|}
\hline \multicolumn{1}{|c|}{ Construct } & Items & $\%$ \\
\hline IT compatibility & 4 & 0.72 \\
\hline IT connectivity & 3 & 0.75 \\
\hline IT Modularity & 3 & 0.74 \\
\hline IT personal & 4 & 0.72 \\
\hline Innovation performance & 12 & 0.72 \\
\hline
\end{tabular}

The first model examines the relationship between independent variables (IT Compatibility, IT connectivity, IT modularity and IT personal) and dependent variables under four hypotheses. Table 4 , shows that the percentage of alteration in the exogenous variable elucidated by the endogenous variables $\left(\mathrm{R}^{2}\right)$ was $59 \%$. The ANOVA table 5 shows that the computed F statistic is $56.37,<0.01$. Thus, the hypothesis that there is no linear association on the exogenous factors and endogenous variable is rejected. The computed F statistic is 52.354, < 0.01, and consequently, the null hypothesis of no association between the predictors and dependent variable is rejected.Table 5, illustrates the overall result of regression analysis for five hypotheses. The correlation between IT compatibility and innovation performance is not significant where $P$. value is $0.066>0.05$. Thus, the null hypothesis that stated there is no significant correlation between IT compatibility and company performance is accepted. Meanwhile, IT connectivity and innovation is positive significant correlated at coefficient $\mathrm{B}=0.169$ and t test of 3.8. IT Modularity and innovation is positive significant correlated at coefficient $\mathrm{B}=0.196$ and t test of 4.4. In addition, IT personal and innovation is positive significant correlated at coefficient $\mathrm{B}=0.304$ and $\mathrm{t}$ test of 5.3

\begin{tabular}{|l|c|c|c|c|c|}
\hline \multirow{2}{*}{} & \multicolumn{2}{|c|}{ Coefficients } & Std & \multirow{2}{*}{$\mathrm{t}$} & \multirow{2}{*}{ Sig. } \\
\cline { 2 - 5 } & $\mathrm{B}$ & $\begin{array}{c}\text { Std. } \\
\text { Error }\end{array}$ & Beta & & \\
\hline & 0.465 & 0.251 & & 1.855 & 0.066 \\
\hline COM & 0.072 & 0.055 & 0.082 & 1.308 & 0.193 \\
\hline CON & 0.169 & 0.044 & 0.241 & 3.805 & 0 \\
\hline MOD & 0.196 & 0.044 & 0.262 & 4.416 & 0 \\
\hline ITP & 0.304 & 0.058 & 0.322 & 5.279 & 0 \\
\hline
\end{tabular}

\section{CONCLUSION}

The past literature has extensively defined the firms' resources in financial capital and non-financial assets leaving a wide literature. However, in the era of the $21^{\text {st }}$ century, the globalization revolution has radically changed the world economy locally as well as in international business. This change was precipitated by the information technology revolution. However, the effectiveness of IT is dependent on its competencies and many studies have suggested a list of competencies that have the ability to bring positive change to the firms. This raises an open question in how can firms attain a maximum advantage from IT to boost their innovativeness that is the key driver for their performance. Many studies emphasized to several aspects where IT competencies can bring new change to the firm performance either in innovation, absorptive capacity, supply chain and etc. However, the past research has not provided a holistic framework that explains under which conditions the IT competencies can bring about a new change to innovation capability. For example, the level of IT competencies on innovation capability can be influenced by the mediating role of several factors such as absorptive capacity, for example. In addition, the level of IT competencies is affected by the firm strategy and culture. 
This paper was conducted to examine the association between information technology infrastructure and innovation capabilities in the SMEs. The majority of previous studies paid a considerable attention on the information technology functions in large corporations, especially in developed countries. However, the technology edge between developed and developing countries is huge and the term of IT functions has not totally explored in some of developing countries with less growth such as Iraq. Therefore, this research conducted in Iraq SMEs in the vital sectors such as oil, energy, communication and food which have the major contribution to GDP in Iraq. The quantitative methodology was conducted and survey employed in data collection. The SPSS through regression analysis was used to analysis the data. The finding of this study emphasizes that IT infrastructure (IT connectivity, modularity and personal) has positive effect on innovation performance in Iraqi SMEs. The finding of this paper brings a new insight in how to improve the capacity of innovation development among SMEs. The application of IT is not only in using the technology, but also in how to use the technology and what competencies that SMEs needs to incorporate.

\section{RESEARCH LIMITATION AND FUTURE RESEARCH}

Despite, the finding of this paper arrived with important application, there are some shortcomings that future studies can further explore. On one hand, the sample size should be increased and most welcome from region rather than one country. There are other variables that may affect the magnitude on innovation performance such as absorptive capacity. Therefore, future research may have to examine the interaction effect of absorptive capacity in both mediating and moderating roles.

\section{REFERENCES}

1. Brunswicker, S. \& Vanhaverbeke, W., 2015. Open Innovation in Small and Medium-Sized Enterprises (SMEs): External Knowledge Sourcing Strategies and Internal Organizational Facilitators. Journal of Small Business Management.

2. Camisón, C. \& Villar-López, A., 2014. Organizational innovation as an enabler of technological innovation capabilities and firm performance. Journal of Business Research, 67(1), pp.2891-2902.

3. Chae, H., Koh, C. \& Prybutok, V., 2014. Information technology capability and firm performance: contradictory findings and their possible causes. MIS Quarterly, 38(1), pp.305-326.

4. Chen, Y. et al., 2017. Improving strategic flexibility with information technologies: Insights for firm performance in an emerging economy. Journal of Information Technology, 32(10), pp.10-25.

5. Cui, T. et al., 2015. Information technology and open innovation: A strategic alignment perspective. Information and Management, 52(3), pp.348-358.

6. Dai, Z., 2008. Supply chain transformation by ERP for enhancing performance - an empirical investigation / Zong Dai. Advances in competitiveness research: $A C R, 16$; Jg. 20(1/2), pp.87-98.
7. Devaraj, S. \& Kohli, R., 2003. Performance Impacts of Information Technology: Is Actual Usage the Missing Link? Management Science.

8. Grant, R.M., 1996. Toward a knowledge-based theory of the firm. Strategic Management Journal, 17(S2), pp.109122.

9. Hashem, I.A.T. et al., 2015. The rise of "big data" on cloud computing: Review and open research issues. Information Systems.

10. Isal, Y. et al., 2016. Analysis of IT infrastructure flexibility impacts on IT-Business strategic alignment. Journal of Industrial Engineering and Management, 9(3), p.657.

11. Koo, C. et al., 2016. Conceptualization of Smart Tourism Destination Competitiveness. Asia Pacific Journal of Information Systems.

12. Ochara, N.M. \& Mawela, T., 2015. Enabling Social Sustainability of E-Participation through Mobile Technology. Information Technology for Development.

13. OECD, 2005. The Measurement of Scientific and Technological Activities: Guidelines for Collecting and Interpreting Innovation Data: Oslo Manual,

14. Ollo-López, A. \& Aramendía-Muneta, M.E., 2012. ICT impact on competitiveness, innovation and environment. Telematics and Informatics, 29(2), pp.204-210.

15. Pérez-López, S. \& Alegre, J., 2012. Information technology competency, knowledge processes and firm performance. Industrial Management \& Data Systems, 112(4), pp.644-662.

16. Quek, G.C.L., 2017. Technology and innovation. In Lee Kuan Yew's Educational Legacy: The Challenges of Success.

17. Rashid, N., \& Shami, S., 2017. The moderating effect of eco product innovation on ISO 14001 EMS and sustainable development. In Proceedings of Mechanical Engineering Research Day 2017,. pp. 262-264.

18. Rashid, N. et al., 2015. State of the Art of Sustainable Development: An Empirical Evidence from Firm's Resource and Capabilities of Malaysian Automotive Industry. Procedia - Social and Behavioral Sciences, 195(2015), pp.463-472. Available at http://linkinghub.elsevier.com/retrieve/pii/S187704281503 9671.

19. Schilling, M.A., 2000. Toward a general modular systems theory and its application to interfirm product modularity. Academy of Management Review, 25(2), pp.312-334.

20. Swanson \& Ramiller, 2017. Innovating Mindfully with Information Technology. MIS Quarterly.

21. Tallon \& Pinsonneault, 2017. Competing Perspectives on the Link Between Strategic Information Technology Alignment and Organizational Agility: Insights from a Mediation Model. MIS Quarterly.

22. Tsuji, M. et al., 2016. Connectivity in the technology transfer process among local ASEAN firms. In 2016 IEEE International Conference on Management of Innovation and Technology, ICMIT 2016.

23. Turulja, L. \& Bajgoric, N., 2016. Innovation and Information Technology Capability as Antecedents of Firms' Success. Interdisciplinary Description of Complex Systems, 14(2), pp.148-156.

24. Wadho, W. \& Chaudhry, A., 2018. Innovation and firm performance in developing countries: The case of Pakistani textile and apparel manufacturers. Research Policy, (April), pp.0-1. Available at http://linkinghub.elsevier.com/retrieve/pii/S004873331830 088X. 